\title{
A Silicon Probe with Integrated Microelectronics for Soil Moisture Measurements
}

\author{
A.Valente, J.Boaventura Cunha ${ }^{1}$, J.H.Correia and C.Couto ${ }^{2}$
}

\begin{abstract}
This work presents an on-chip silicon bulk-micromachined Soil Moisture Sensor (SMS) suited for irrigation control and management applications. The same basic fabrication concepts and materials, which made microelectronics successful, are now being adapted to making low-cost, small, high-performance sensor systems with integrated electronics on the same chip. As a result, this system-on-a-chip includes the SMS, readout electronics, self-test, calibration facilities and a digital bus interface for external data transmission. Moreover, since this sensor has low-cost, it could be employed several sensors networked together with the 1-wire bus, to achieve an accurate measure of the soil moisture at the plant root level. A heat-pulse technique is used (for measuring the maximum temperature on a distant point) to determine the volumetric heat capacity and hence the water content of a porous media, such as soil. This method is based on the Joule effect (heater probe shank) and in Seebeck effect (thermopile - temperature probe shank). The heater and the thermopile are suspended on a dielectric window to reduce undesired heat conduction to the substrate (silicon is a good heat conductor). Thermal simulations of the bulk-micromachined SMS are performed to test sensor performance. In order to validate the method, simulations are made and experimental results were achieved with a macrosensor based on this technique. The results were compared with the measurements performed by the conventional thermo-gravimetric method.
\end{abstract}

Keywords: Instrumentation and Control, Water Management, Microsensors

\footnotetext{
${ }^{1}$ A.Valente and J.Boaventura Cunha, Instrumentation and Control Group, University of Trás-os-Montes and Alto Douro, Vila Real, P-5000 Vila Real, Portugal, avalente@utad.pt

2 J.H. Correia and C. Couto, Department of Industrial Electronics, University of Minho, Guimarães, P-4800, Guimarães, Portugal.
} 


\section{Introduction}

Irrigators are under increasing pressure to manage water more prudently and more efficiently. This pressure is driven by product quality requirements, economic factors, demands on labor and the desire to minimize the resource degradation and yield loss that can result from inefficient irrigation. The need for farmers to irrigate more efficiently has led to an explosion in the range of equipment available for measuring soil water status (Charlesworth, 2000).

Today, a large number of sensors, based on different methods: nuclear, electromagnetic, tensiometric, capacitance, are available for measuring soil moisture. Generally, these methods have several limitations that restrict their integration in irrigation systems. Among others, the main disadvantages are: soil dependency, inaccuracy and high cost.

Time domain reflectometer (TDR) sensors, which are based on the influence of soil water content over the propagation of electromagnetic waves, are independent of soil texture, temperature and salt content, but its high cost restricts the applicability to these systems (Topp et. al., 1980, Topp and Davis, 1985). Therefore, the development of a miniaturized system with electronics, network solution, low-cost, with external communications and allowing its implantation next to the plant roots will be a breakthrough.

The same basic fabrication concepts and materials, which have made microelectronics successful, are now being adapted to making low-cost, small, high-performance sensor systems devices, e.g. a silicon bulk-micromachined soil moisture sensor. The compatibility with CMOS standard fabrication processing allows integrating the sensor and electronics in the same chip.

\section{Theory}

The heat capacity of soil, $\rho c_{p}$, is evaluated by adding the volumetric heat capacities of the soil constituents:

$$
\rho c_{p}=1.92 X_{m}+2.51 X_{o}+4.18 \theta_{v}
$$

where $X_{m}, X_{o}$, and $\theta_{v}$ are the mineral, organic, and water fractions of the soil, respectively. The leading coefficients represent the volumetric heat capacity $\left(\mathrm{MJm}^{-30} \mathrm{C}^{-1}\right)$ of each soil constituent. When the pulse of heat is applied during a fixed interval of time to the line source (heater probe), the maximum rise in temperature $\left(\Delta T_{m}\right)$ at some distance from the line source is measured (temperature probe). The relationship between the $\rho c_{p}$ and $\Delta T_{m}$ is (Campbell et. al., 1991),

$$
\rho c_{p}=\frac{q}{e \pi r^{2} \Delta T_{m}}
$$

where, $q\left(\mathrm{Jm}^{-1}\right)$ is the heat applied per unit length of the line source, $e$ is the base of natural logarithms, and $r(\mathrm{~m})$ is the distance between the heat and temperature probes. Providing, that the ratio of heater half-length to temperature probe spacing $(b / r)$ is greater than to 2.5 , we could assume $(0.14 \%$ error $)$ that the probe heater is 
infinite. In addition, the ratio of heater radius to temperature probe spacing $(a / r)$ is less than 0.06 , and the heating duration is less than $8 \mathrm{~s}$, we minimize the errors and support the use of Campbell model Eq. (2) as a model for determining heat capacity (Kluintenberg et. al., 1993). Substituting Eq. (1) into Eq. (2) and rearranging yields an expression that shows the relationship between $\theta_{v}$ and $\Delta T m$,

$$
\theta_{v}=\frac{\frac{q}{e \pi r^{2} \Delta T_{m}}-\left(1.92 X_{m}+2.50 X_{o}\right)}{4.18}
$$

or,

$$
\Delta T_{m}=\frac{q}{e \pi r^{2}\left(1.92 X_{m}+2.50 X_{o}+4.18 \theta_{v}\right)}
$$

Figure 1 shows that a $q$ value of $50 \mathrm{Jm}^{-1}$ produces a span of $0.5^{\circ} \mathrm{C}$ over the entire range of $\theta_{v}$, while for $q=200 \mathrm{Jm}^{-1}$ the span is about $1.5^{\circ} \mathrm{C}$.

The partial derivate of $\Delta T_{m}$ with respect to $\theta_{v}$ yields an expression of the sensitivity of the temperature rise with respect to the change in soil water content:

$$
\frac{\partial \Delta T m}{\partial \theta_{v}}=\frac{-4.18 q}{e \pi r^{2}\left(1.92 X_{m}+2.50 X_{o}+4.18 \theta_{v}\right)^{2}}
$$

Considering the range of water content (typical agricultural soil -0.05 to $0.35 \mathrm{~m}^{3} \mathrm{~m}^{-3}$ ) and the common sensitivities of integrated thermopiles to be $50 \mathrm{mV} /{ }^{\circ} \mathrm{C}$ (van Herwaarden et. al., 1989) then a $1 \%$ change in $\theta_{v}$ would cause a change in the electrical signal depending on $q$ (Fig.2). Sensitivity of $\Delta T_{m}$ decreases as less energy is applied to the probe $(q)$, so the use of less supply will imply the need to use an A/D converter with more resolution to maintain accuracy. Previous studies show that a minimum of $0.5^{\circ} \mathrm{C}$ for $\Delta T_{m}$ is a good choice (Bilskie, 1994).

\section{Experiments}

The heat-pulse macro device used in this study to test the DPHP method is illustrated schematically in Fig. 3.

It consists of two needle probes mounted in parallel to provide a heater and a sensor probe, as reported by Tarara and Ham (1997) and Song et. al. (1998). The needles were made from stainless steel tubing, $0.912 \mathrm{~mm}$ in diameter, which protrude $20 \mathrm{~mm}$ beyond the edge of the acrylic mounting. Spacing is $3 \mathrm{~mm}$ between the heater and the sensor probe.

The heater was made from enameled Stablohm 800 wire $(0.062 \mathrm{~mm}$ diameter and $440.8 \Omega \mathrm{m}^{-1}$ of resistivity), which was pulled into the heater needle. The heater resistance is $33.76 \Omega$. Copper-constantan thermocouple was pulled into and centered in the sensor needle. The needles were then filled with high-thermal-conductivity epoxy glue to provide water-resistant, electrically insulated probes.

The heat pulse was generated by applying voltage $(12 \mathrm{~V})$ from a direct current supply to the heater for a fixed period $(3 \mathrm{~s})$. This gave a nominal value for $\mathrm{q}$ of 167 
$\mathrm{Jm}^{-1}\left[(12 \mathrm{~V} / 33.76 \Omega)^{2} \cdot 440.8 \Omega \mathrm{m}^{-1} \cdot 3 \mathrm{~s}\right]$. A data acquisition system based on a micro-controller and a sigma-delta ADC, controlled the heat pulse, monitored the current through the heater, measured the temperature of the thermocouple, and recorded the average power and the maximum temperature.

Soil samples of Almendra silt loam, which were wet to a predetermined water content and mixed, were packed into a cylinder $77 \mathrm{~mm}$ in diameter by $70 \mathrm{~mm}$ long, with the soil moisture macro sensor at the center. Measurements were taken and then the soil was weighed and dried at $105^{\circ} \mathrm{C}$ for $24 \mathrm{~h}$ to determine bulk density and water content (thermo-gravimetric method),

\section{Results}

$$
\theta=\frac{(\text { wet weight })-(\text { dry weight })}{\text { dryweight }}
$$

Table 1 lists the thermo-gravimetric soil water content $\left(\theta_{g}\right)$ and the measured values; maximum temperature rise $\left(\Delta T_{m}\right)$ and the heat applied per unit length of the line source $(q)$.

In soils with low organic matter, such as Almendra, $X_{o}$ is neglected. The value of $X_{m}$ is determined by dividing the soil bulk density by the particle density. An average value of $2.65 \mathrm{Mgm}^{-3}$ is often used for particle density of soils. Therefore, using Eq. 3 the calculated values $\left(\theta_{v}\right)$ of soil water content are in good agreement with thermo-gravimetric values.

Figure 4 shows typical temperature by time data for heat-pulse measurements.

\section{Discussion}

Figure 5 shows the designed sensor. The sensor is implemented in a post-processing step (silicon bulk--micromachining with $\mathrm{KOH}$ as etchant) after a CMOS standard process for the fabrication of readout electronics (Correia et. al., 1999).

Silicon has a large thermal conductivity (about $156 \mathrm{Wm}^{-1} \mathrm{~K}^{-1}$ ) and produces a thermal short-circuit between the heater-probe and the temperature-probe. High-performance thermoelectric sensors require a proper insulation between the 'hot' and 'cold' junction of the thermocouples. Therefore, silicon dioxide and silicon nitride (low thermal conductivity, 2 to $3 \mathrm{Wm}^{-1} \mathrm{~K}^{-1}$ ) are used for embedding the probes. A thermal isolator glass is used in the packaging of the probes.

Needles are then inserted into the heater and sensor probes and then filled with high-thermal-conductivity epoxy glue. The upper part of the sensor (the readout circuit) is filled with a very low thermal conductivity epoxy glue to provide water resistance and electrical insulation.

\section{Conclusions}


The design and modeling of a silicon bulk-micromachined soil moisture microsensor using the Dual-Probe Heat-Pulse (DPHP) method were achieved. The DPHP method showed to be the most appropriate to measure humidity at different soil depths, and therefore, close to the surface of the soil in a non-destructive and automated manner. This is the first time that the DPHP method is implemented in a microdevice and the first integrated sensor for soil moisture. A fabrication plan for a prototype, elaborated for a Europractice manufacturing cluster, is in the test phase an soon a prototype will be made and tested.

The DPHP sensor is about $30 \mathrm{~mm}$ long by $6 \mathrm{~mm}$ wide by $0.8 \mathrm{~mm}$ in height; the probe pitch is $3 \mathrm{~mm}$ for allowing small-scale spatial measurements of $\theta_{v}$, which can be made near the soil surface where large root densities are found. 


\section{References}

Bilskie, J.R. 1994. Dual probe methods for determining soil thermal properties: Numerical and laboratory study. Ph.D. diss. Iowa State Univ. Ames (Diss. Abstr. 9503532).

Campbell, G.S., C. Calissendorff, and J.H. Williams 1991. Probe for measuring soil specific heat using a heat-pulse method. Soil Sci. Soc. Am. J. 55:291-293.

Charlesworth, P. 2000. Soil Water Monitoring. Irrigation Insights. pp.1

Correia, J.H., G. de Graaf, S. H. Kong, M. Bartek, R. F. Wolffenbuttel 1999.

Single-chip CMOS optical microspectrometer. Transducers'99. pp.896-899.

Kluitenberg, G.J., J.M. Ham, and K.L. Bristow 1993. Error analysis of the heat pulse method for measuring soil volumetric heat capacity. Soil Sci. Soc. Am. J. 57:1444-1451.

Song, Y., J.M. Ham, M.B. Kirkham, and G.J. Kluitenberg 1998. Measuring soil water content under turfgrass using the dual-probe heat-pulse technique. J. Amer. Soc. Hort. Sci. 123(5):937-941.

Tarara, Julie M., and Jay M. Ham 1997. Measuring soil water content in the laboratory and field with dual-probe heat-capacity sensors. Agronomy Journal. 89:535-542.

Topp, C. G., J. L. Davis and A. P. Annan 1980. Electromagnetic determination of soil water content using TDR: Measurements in coaxial transmission lines. Water Resour. Res. 16:574-582.

Topp,C. G., J. L. Davis. 1985. Measurement of soil water content using time-domain reflectometry (TDR): A field evaluation. Soil Sci. Soc. Am. J. 49:19-24.

van Herwaarden, A.W., D.C. van Duyn, B.W. van Oudheusden, and P.M. Sarro 1989. Integrated Thermopile Sensors. Sensors and Actuators. A21-A23:621-630.

\section{Tables}


Table 1: Soil water contents calculated using Eq.3.

\begin{tabular}{cccc}
\hline \hline $\begin{array}{c}\boldsymbol{\theta}_{\boldsymbol{g}} \\
\left(\boldsymbol{m}^{\mathbf{3}} \boldsymbol{m}^{-3}\right)\end{array}$ & $\begin{array}{c}\boldsymbol{\Delta} \boldsymbol{T}_{\boldsymbol{m}} \\
\left({ }^{\mathbf{0}} \mathbf{C}\right)\end{array}$ & $\begin{array}{c}\boldsymbol{q} \\
\left(\mathbf{J m}^{-\mathbf{1}}\right)\end{array}$ & $\begin{array}{c}\boldsymbol{\theta}_{\boldsymbol{v}} \\
\left(\boldsymbol{m}^{3} \boldsymbol{m}^{-3}\right)\end{array}$ \\
\hline 0 & 1.25 & 100 & 0 \\
0.1 & 0.88 & 100 & 0.106 \\
0.2 & 0.71 & 100 & 0.190 \\
0.3 & 0.56 & 100 & 0.308 \\
0.4 & 0.48 & 100 & 0.401 \\
\hline \hline
\end{tabular}




\section{Figures}

\section{${ }^{\mathrm{DT}} \mathrm{I}_{\mathrm{m}} \mathbf{L}$}

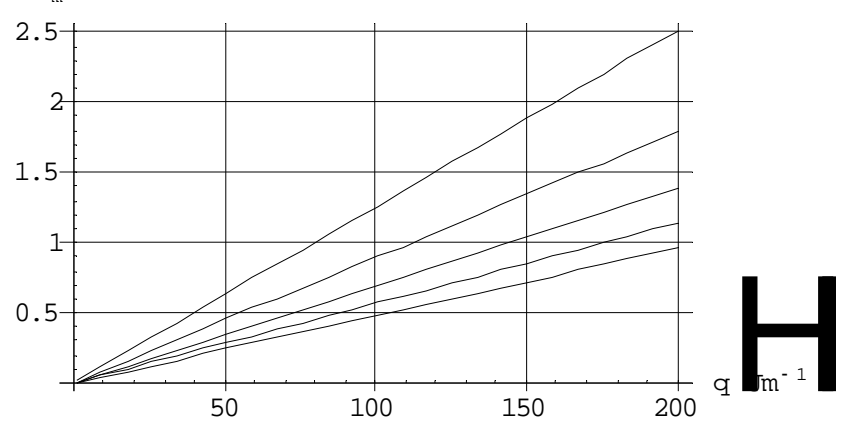

Figure 1. Variation of temperature for different values of heat applied in a typical agricultural soil.

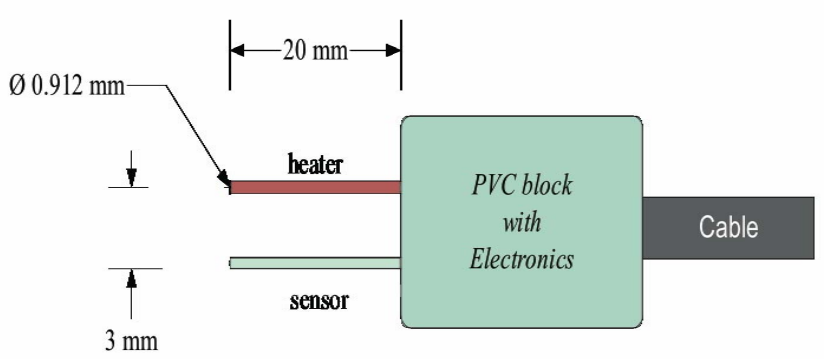

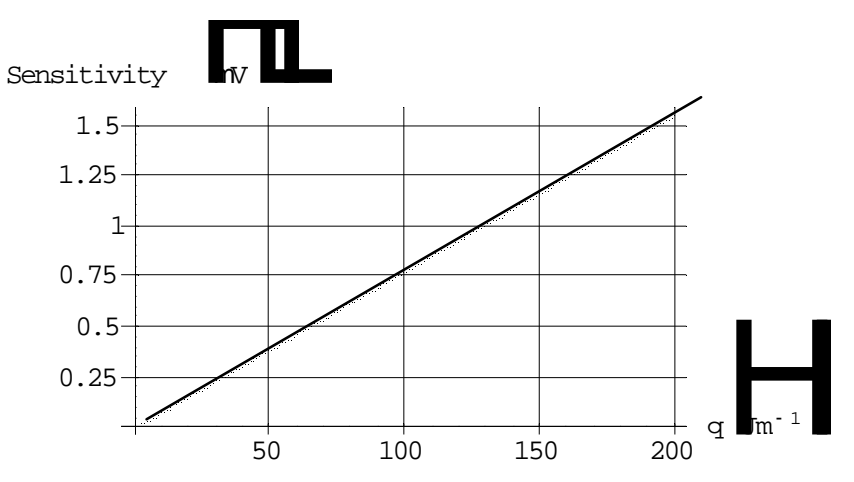

Figure 2. Sensitivity considering variation of $1 \%$ in soil water content.

Figure 3. Sketch of the soil moisture macrosensor.

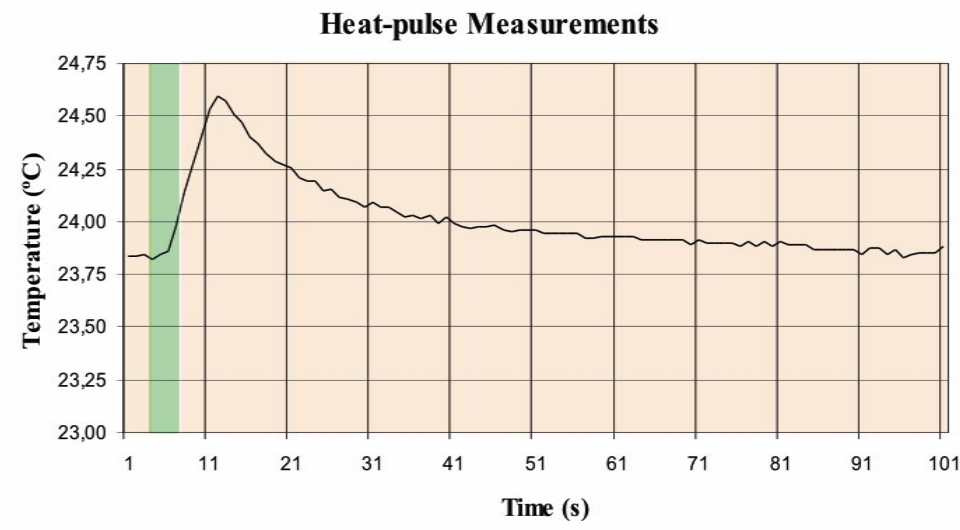

Figure 4. Typical temperature by time data obtained for $0.1 \mathrm{~m}^{3} \mathrm{~m}^{-3}$ of volumetric water content and a heat-pulse(marked) of $3 \mathrm{~s}$.

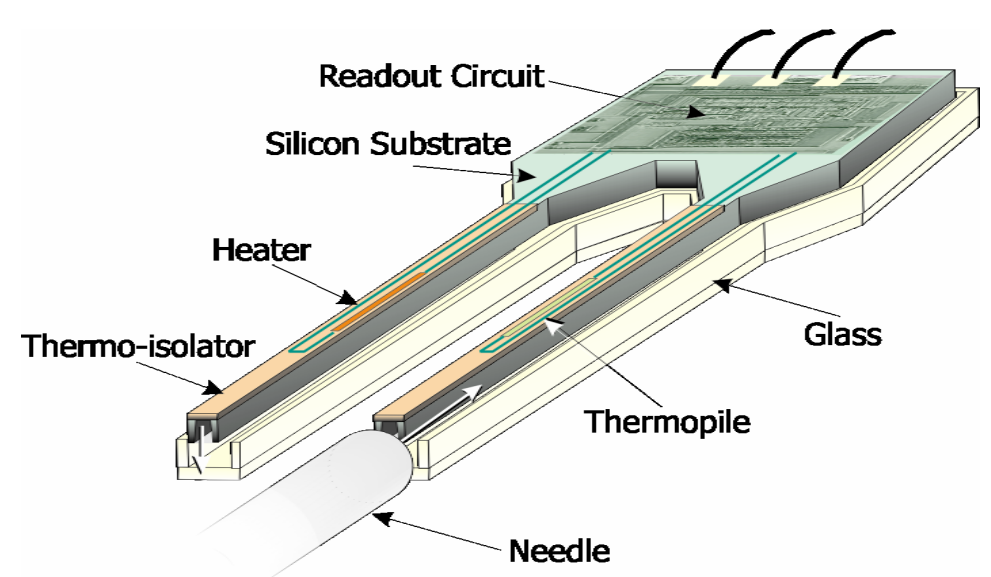

Figure 5. The designed soil moisture sensor with readout electronics. 